(2) Open Access Full Text Article

ORIGINAL RESEARCH

\title{
Improving Person-Centred Leadership: A Qualitative Study of Ward Managers' Experiences During the COVID-19 Crisis
}

This article was published in the following Dove Press journal: Risk Management and Healthcare Policy

\author{
Bibi Hølge-Hazelton $\mathbb{D}^{1,2}$ \\ Mette Kjerholt $\mathbb{1}^{3}$ \\ Elizabeth Rosted $\left(\mathbb{D}^{2,4}\right.$ \\ Stine Thestrup Hansen (1D ${ }^{5}$ \\ Line Zacho Borre (iD) \\ Brendan McCormack (D) ${ }^{6}$ \\ 'Research Support Unit, Zealand \\ University Hospital, Roskilde, Denmark; \\ ${ }^{2}$ Department of Regional Health \\ Research, University of Southern \\ Denmark, Odense, Denmark; \\ ${ }^{3}$ Department of Hematology, Zealand \\ University Hospital, Roskilde, Denmark; \\ ${ }^{4}$ Department of Oncology and Palliative \\ Care, Zealand University Hospital, \\ Roskilde, Denmark; ${ }^{5}$ Department of \\ Plastic Surgery and Breast Surgery, \\ Zealand University Hospital, Roskilde, \\ Denmark; ${ }^{6}$ Centre for Person-Centred \\ Practice Research, Queen Margaret \\ University Edinburgh, Musselburgh, East \\ Lothian, UK
}

Correspondence: Bibi Hølge-Hazelton

Research Support Unit, Zealand

University Hospital, Munkesøvej 14,

Roskilde, 4000, Denmark

Tel +45 27/24286

Email bibh@regionsjaelland.dk
Purpose: In order to provide guidance and prepare ward managers for future crisis situations similar to the COVID-19 pandemic, the aim of this study was to reflect and learn how person-centred nursing leadership may be strengthened in such situations.

Background: The pandemic has forced nurse leaders to face new challenges. Knowledge about their experiences may contribute to advancing leadership practices in times of future crises.

Methods: A qualitative directed content analysis was chosen. The theoretical perspective was person-centred leadership. Thirteen ward managers from a Danish university hospital were included and interviewed using telephone interviews three months after the first national COVID-19 case was confirmed.

Findings: The main findings of the study revealed that the ward managers often experienced a lack of timely, relevant information, involvement in decision-making and acknowledgement from the head nurse of department and the executive management. This was caused by the existing organizational cultures and the traditional hierarchy of communication. This meant that the ward managers' sense of own competences and leadership values and beliefs came under high pressure when they had to balance different stakeholders' needs.

Conclusion: When the experience of ward managers results in them being unable to lead authentically and competently in a crisis like the COVID-19 pandemic, lack of engagement can occur, with serious consequences for patients, staff and the ward managers themselves. Traditional organizational cultures that are hierarchical and controlling needs to be challenged and reoriented towards collaborative, inclusive and participative practices of engagement and involvement. Leadership development must be an established and integrated component of organizations, so that ward managers are able to sustain person-centred ways of being and doing in times of crisis.

Keywords: pandemic, crisis management, qualitative research, person-centred practice, nursing

\section{Plain Language Summary}

This study was initiated to obtain knowledge about ward managers' experiences during the COVID-19 pandemic in order to contribute to advancing leadership practices in times of future crises. Thirteen ward managers were interviewed by telephone three months after the first national COVID-19 case was confirmed. The findings revealed that the ward managers often experienced a lack of timely, relevant information, involvement in decision-making and acknowledgement from their executive leaders. This meant that the ward managers' sense of own competences and leadership values and beliefs came under high pressure, when they had 
to balance different stakeholders' needs. Leadership development must be an established and integrated component of organizations, so that ward managers can enhance their capacity to manage effectively in times of crisis.

\section{Introduction}

The global spread of coronavirus (COVID-19) has challenged and changed healthcare systems worldwide. ${ }^{1}$ It is expected that the pandemic may hit in several waves in the next year and healthcare systems must be prepared for these waves. ${ }^{2}$ In nursing, a group of international nurse leaders highlighted the need for visible person-centred nursing leadership during the COVID-19 pandemic. ${ }^{3,4}$ These leaders argue strongly for reflection on and learning from the current crisis, in order to identify how nursing leadership may be strengthened in future times of crisis.

The study reported in this paper can be seen as a response to that challenge. It was initiated after the completion of an interdisciplinary cross-sectional survey that included healthcare leaders who worked at a University Hospital in Denmark during the COVID-19 pandemic. ${ }^{5}$ The survey focused on four overall themes that are known to be among the key ingredients of successful crisis management: i) communication, ii) coordination and decision-making, iii) collaboration, and iv) concerns.

One hundred and sixty hospital leaders were invited to complete the survey and a response rate of $72 \%$ was achieved. Significant differences were found in three selected characteristics: i) management level, ii) management education and iii) years of experience. Particularly the nursing ward managers experienced being challenged during the COVID-19 pandemic compared with the head of departments. Additionally, they experienced being less able to work in a way that was consistent with their leadership beliefs and values. ${ }^{5}$

The study concluded that despite the uniqueness of the COVID-19 situation, it shone a light on the already known importance of organizations having a thorough understanding of the knowledge, skills and experiences of their leaders and their need for support at times of crisis. ${ }^{5}$ It is also known that despite having limited power and authority and often unclear roles, purpose and functions nurse ward managers have a major impact on the quality of care patients receive and on the wellbeing and turnover of nurses. ${ }^{6-9}$ Given the emphasis on person-centred care in the organization in which the research took place, the results of the questionnaire generated an opportunity to explore person-centred leadership in times of crisis. ${ }^{10}$

\section{Aim}

The aim of this study was to elaborate on the experiences of nursing ward managers during and after the COVID-19 pandemic in order to reflect and learn how person-centred nursing leadership may be strengthened in future times of crisis.

\section{Methods}

The study was a descriptive study using interviews via a semi-structured interview guide (Appendix 1). This paper is based on qualitative methods and reports results from the interviews. The Consolidated criteria for reporting qualitative research (COREQ) checklist is used for reporting the methods and findings. ${ }^{11}$

\section{Setting}

The study took place at a University Hospital in Denmark. The hospital has 24 departments with 738 beds across four different locations. Sixty ward managers are employed in the organization. The nursing hierarchy at the hospital is similar to other hospitals in Denmark. At the top, the executive management level consists of the CEO and three hospital directors. At the next level, the heads of the 24 departments are found, usually a head nurse and a chief physician. The departments consist of one to several units, each lead by a ward manager. At the bottom of the hierarchy, the staff nurses and other staff members are found. Figure 1 gives a simplified picture of the nursing leadership structure.

In the hospital's vision and strategy for nursing and allied health, it is underlined that treatment and care should be person-centred and adjusted to the specific context. $^{12}$

In February 2020, the first COVID-19 case nationally was confirmed at this hospital. This resulted in an immediate organizational response coordinated according to the national and WHO 6-phase pandemic strategy, including an emergency leadership committee that coordinated and modified the infrastructure at the hospital and establishing two COVID-19 units at different locations as well as a test center. ${ }^{13}$ One of the COVID-19 units was established at an existing medical unit, which included the ward manager, some of the permanent staff, staff transferred from other departments, and trained staff from outside the hospital. The other COVID-19 unit was established in a department created for this purpose. Here the ward manager was transferred from another department and all staff moved 


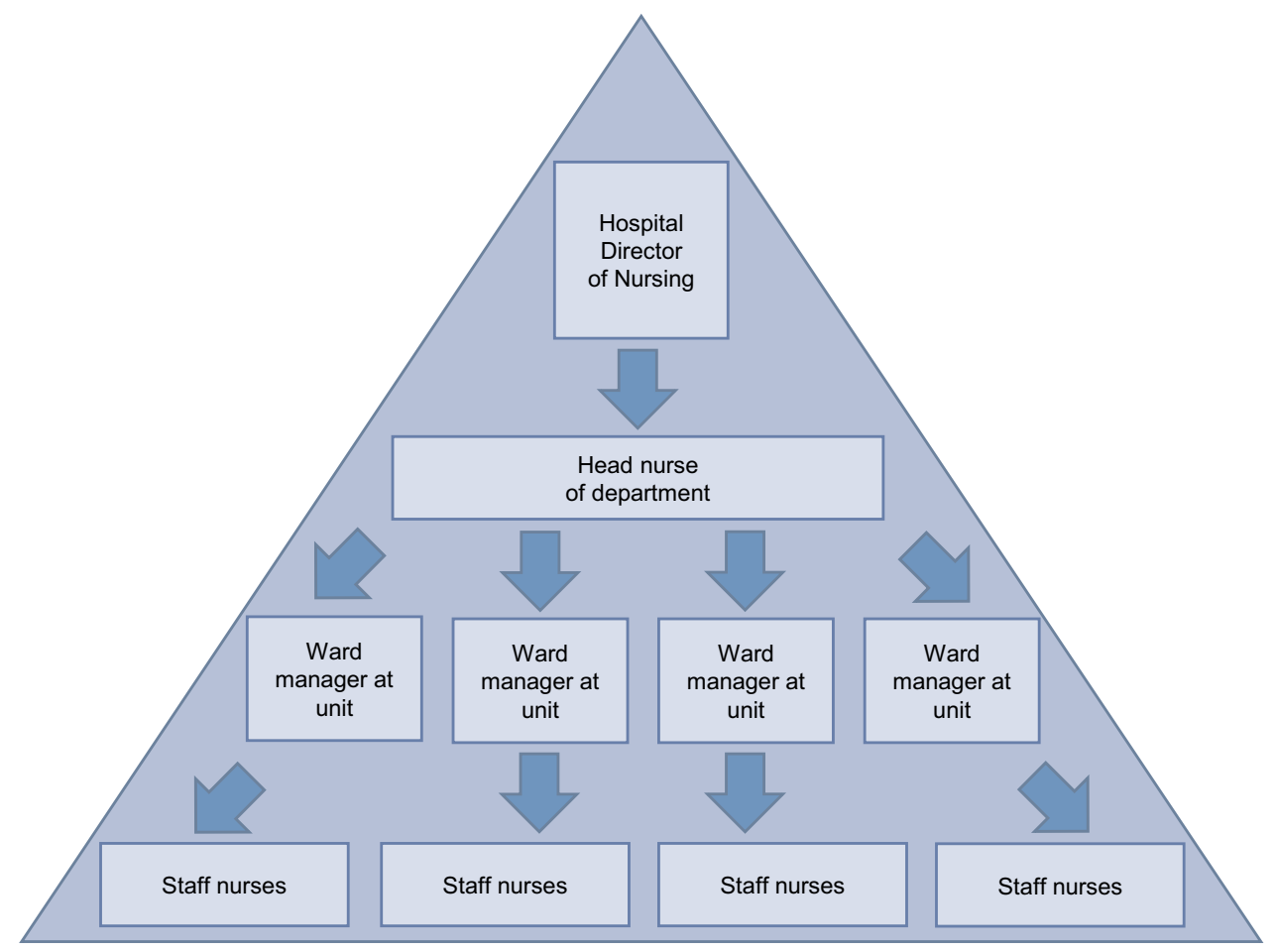

Figure I The nursing leadership hierarchy at the hospital.

and recruited from different departments across the hospital. All other clinical departments at the hospital were affected by the COVID-19 pandemic. This was either directly when receiving, treating and caring for patients who were either under observation for or diagnosed with COVID-19 or indirectly when having to assign new tasks or move staff to COVID-19 units.

\section{Participants}

All nurse ward managers who completed the initial crosssectional survey examining health care leaders' experiences during the COVID-19 pandemic, and who volunteered to participate in a follow-up interview, were invited to participate in this study. ${ }^{14}$

\section{Theoretical Perspective}

The theoretical perspective is inspired by personcentredness. ${ }^{15}$ This perspective is rooted in the critical paradigm and is aimed at supporting leadership practices that make person-centred values live in the organization. ${ }^{16}$ Person-centred leadership research is therefore both normative and action driven. ${ }^{10}$ Questions in person-centred leadership research should be concerned with organizational as well as relational domains. ${ }^{17}$ In this case, the questions were related to attributes of person-centred leadership including clarity of beliefs and values, creating a sense of community, balancing different stakeholder needs, shared decision-making and commitment to personal development.

\section{Interview Method}

Telephone interviews were chosen as they were the most viable method in the situation for collecting information about sensitive topics in workplaces. ${ }^{18,19}$ Further, they were convenient and safe for participants as well as researchers who were limited in relation to meetings due to COVID-19 restrictions. A semi-structured interview guide was developed and amended prior to the first interview, based on a pilot interview. ${ }^{20}$ The guide was developed based on key findings from the original study and on person-centred leadership theory. ${ }^{14,17}$ The guide can be seen in Appendix 1.

The interviews were recorded by the researcher conducting the interview, who made notes to highlight specific issues of importance. To facilitate ease of communication and prepare the ward managers, they received the interview questions by e-mail at least two days prior to the interview, including information about the researcher's name and background. ${ }^{19}$ All authors except one, who did not speak Danish, conducted two to three interviews each. 
All interviewers were female, all had a PhD-degree except for one who had an MSc and all had extensive experience of undertaking research interviews. The interviewers were matched with ward managers they did not know or work with directly. The participants subsequently received a report in Danish based on the results from the interviews.

The interviews took place from 17 to 30 June 2020, approximately three months after the first COVID-19 case was confirmed. Interviews lasted between 17 and 59 minutes depending on how much the participants wished to talk about their experiences.

\section{Data Analysis}

A directed content analysis was used to analyze interview data. Directed content analysis creates a description of data based on predetermined themes in order to investigate certain areas of a problem. ${ }^{21}$ This manifest description of data is guided by a structured process starting with identifying key concepts as initial coding categories. ${ }^{21}$ In this study, the area of interest was to reflect on and learn how person-centred leadership may be strengthened in future times of crisis via an in-depth elaboration of the experiences of nursing ward managers during and after the COVID-19 pandemic. Therefore, the predetermined themes were related to person-centred leadership theory including i) beliefs and values; ii) creating a sense of community; iii) balancing different stakeholder needs; iv) shared decision-making; and v) being committed to personal development. ${ }^{17}$

Transcripts of the interviews were carefully read and analysed by the Danish-speaking authors. In the second read-through, the authors independently focused on the five theoretical predetermined themes.

Data that could not be coded within the initial themes were analysed later in order to determine if they represented subcategories of an existing code or a new theme. ${ }^{21}$ During this process, it was determined that all data could be coded within the initial five pre-determined themes.

The analysis was undertaken in Danish and when final codes were agreed, selected quotes to illustrate the themes and sub-themes were translated into English and translations were agreed by all authors. Participant quotes are included to support the analysis but are not equally distributed among the participants.

\section{Findings}

Of the 19 invited ward managers, 13 decided to participate in the telephone interviews. Characteristics of the final 13
Table I Characteristics of the Participating Ward Managers. All the Participants Were Female and with a Mean Age of 48 Years (Range 33-6I)

\begin{tabular}{|l|l|l|l|}
\hline Participants & $\begin{array}{l}\text { Formal } \\
\text { Leadership } \\
\text { Education }\end{array}$ & $\begin{array}{l}\text { Years of } \\
\text { Leadership } \\
\text { Experience }\end{array}$ & $\begin{array}{l}\text { Directly or } \\
\text { Indirectly } \\
\text { Involved in } \\
\text { CoVID-19 }\end{array}$ \\
\hline WM-A & No & $0-2$ & Indirectly \\
\hline WM-B & Yes & $>5$ & Directly \\
\hline WM-C & Yes & $3-5$ & Indirectly \\
\hline WM-D & Yes & $>5$ & Indirectly \\
\hline WM-E & No & $0-2$ & Directly \\
\hline WM-F & Yes & $3-5$ & Indirectly \\
\hline WM-G & Yes & $3-5$ & Directly \\
\hline WM-H & Yes & $>5$ & Indirectly \\
\hline WM-I & Yes & $3-5$ & Indirectly \\
\hline WM-J & Yes & $>5$ & Directly \\
\hline WM-K & Yes & $>5$ & Directly \\
\hline WM-L & Yes & $>5$ & Indirectly \\
\hline WM-M & Yes & $3-5$ & Indirectly \\
\hline
\end{tabular}

participants are shown in Table 1. Participants are identified as ward managers A to M (WM-A to WM-M).

The main findings of the study revealed that the ward managers often experienced a lack of timely, relevant information and acknowledgement from the head of departments. This meant that the ward managers' sense of own competences and leadership values and beliefs came under pressure. The findings are presented as five themes (Figure 2): Leadership beliefs and values; sense of community; balancing different stakeholder needs; involvement in decision-making; and personal development.

\section{Theme I: Leadership Beliefs and Values Maintaining Presence, Own Leadership Virtues and Professionalism}

When asked to describe their leadership beliefs and values and how these worked during the COVID-19 situation, the ward managers spoke about the value of "being present" for their staff, for instance being available or accommodating at almost all times. 


\begin{tabular}{|c|c|c|c|c|}
\hline $\begin{array}{l}\text { Theme 1: } \\
\text { Leadership Beliefs and } \\
\text { Values }\end{array}$ & $\begin{array}{c}\text { Theme } 2 \text { : } \\
\text { Sense of Community }\end{array}$ & $\begin{array}{l}\text { Theme 3: } \\
\text { Balancing Different } \\
\text { Stakeholder Needs }\end{array}$ & $\begin{array}{c}\text { Theme 4: } \\
\text { Involvement in Decision } \\
\text { Making }\end{array}$ & $\begin{array}{c}\text { Theme } 5 \text { : } \\
\text { Personal Development }\end{array}$ \\
\hline $\begin{array}{l}1.1 \text { Maintaining } \\
\text { presence, own } \\
\text { leadership virtues and } \\
\text { professionalism }\end{array}$ & $\begin{array}{c}2.1 \text { Sense of community } \\
\text { at unit level }\end{array}$ & $\begin{array}{l}\text { 3.1 Staff needs versus } \\
\text { overall needs }\end{array}$ & $\begin{array}{c}\text { 4.1 Top-down decision } \\
\text { making }\end{array}$ & $\begin{array}{l}\text { 5.1 Being on a steep } \\
\text { learning curve }\end{array}$ \\
\hline $\begin{array}{l}\text { 1.2 Designating and } \\
\text { transferring staff }\end{array}$ & $\begin{array}{l}2.2 \text { Sense of community } \\
\text { at ward manager level }\end{array}$ & $\begin{array}{l}3.2 \text { Loyalty to own } \\
\text { leaders versus staff } \\
\text { need }\end{array}$ & $\begin{array}{l}\text { 4.2 Bottom up decision } \\
\text { making }\end{array}$ & $\begin{array}{l}\text { 5.2 Management } \\
\text { education give valuable } \\
\text { tools }\end{array}$ \\
\hline $\begin{array}{l}\text { 1.3 Practicing distance } \\
\text { leadership }\end{array}$ & $\begin{array}{c}2.3 \text { Sense of community } \\
\text { at executive level }\end{array}$ & $\begin{array}{c}3.3 \text { Upholding } \\
\text { guidelines versus } \\
\text { relatives and patients' } \\
\text { needs }\end{array}$ & & $\begin{array}{c}\text { 5.3 Personal- } \\
\text { development - rewound }\end{array}$ \\
\hline
\end{tabular}

Figure 2 Thematic Elaboration of Ward Managers' Experiences During COVID-19

I had the phone under the pillow at night as the employees should to be able to call at all hours of the day - and they did. (WM-G)

The ward managers also spoke about the leadership virtues they usually strived to practice, for instance being authentic, engaging, motivating, understanding, humble, open, direct involving, confident, transparent, or open to own and others' vulnerability. Some ward managers spoke about the value of their professionalism, including being a knowledgeable and reflective leader.

It is one of my values to be open about I do not know it all. I am very humble and aware of staff who know more than I and I often say: I honestly don't know the answer to this, but let us investigate it or ask a friend. (VM-D)

\section{Designating and Transferring Staff - Puts Leadership Values Under Pressure}

All except one ward manager explained that acting in accordance with their own values was challenged during the COVID-19 situation. A described and returning challenge was having to designate and transfer own staff to a COVID-19 unit, or receiving staff who had not volunteered to be transferred. This created experiences of having one's leadership values compromised.

My own values have been overruled. The staff were frightened, nervous and crying, but I had to use my professional side not my emotional side when deciding whom to transfer to COVID-19 units (...) and I have been much less empathetic - and much more tough. I would like to strive to change this balance ... but I did not have room or time for discussions in the acute situation. (WM-C)

\section{Practicing Distance Leadership}

Another challenge to the ward managers' values was the unclear leadership responsibilities for the transferred staff. Some of the ward managers described that their transferred staff contacted them daily regarding concerns and questions and that they as leaders felt powerless because they were only able to listen to, not act or lead.

My role has been very unclear. How much leadership was I responsible for? Should I lead the transferred nurses who were sad and contacted me? (WM-D)

Some of the ward managers had to rearrange their units to receive COVID-19 patients including transferred staff, or were transferred themselves to lead newly established COVID-19 units. These ward managers suddenly had to adjust to a new situation in a new or changed context, including having responsibility for staff who had been transferred and who only stayed in the department for two weeks before they returned to their usual units.

The leadership I usually practice has been set on hold. It is difficult to be leader for someone you don't know, and you are alone on the post and you get a new group of staff every fortnight. Suddenly my working week lasted 70 hours because I prioritized taking care of the staff. (WM-G) 


\section{Theme 2: Sense of Community}

The COVID-19 situation had a major impact on the ward managers' sense of community. This was experienced differently at unit, ward manager or executive levels.

\section{Sense of Community at Unit Level}

At unit level, the ward managers experienced a strong sense of community among the staff nurses, especially at the beginning of the COVID-19 pandemic. This could be experienced as a unity concentrated around the ward manager.

In relation to my own staff, I found that they simply moved together in unity. I also felt personally, that they wanted to help me - we played for each other. (WM-H)

Other ward managers experienced a sense of community among the staff against them.

I became the scapegoat for the leaders, because I am the one, who is nearest. (...) I have had to learn to live with not being supported from my staff and I have wondered if I should be a leader at all. (WM-E)

The sense of community was also described as strong among the staff transferred out of units to the COVID-19 functions, especially when they returned to their own units with new collective experiences. Some described how their usual staff were divided and transferred to different tasks, resulting in a sense of splitting, while other ward managers described a strong sense of resourcefulness among those transferred at the beginning. However, this faded as time went by.

In the beginning, there was a sense of community, a sense of gumption. It was like sprinting, where you want to run as fast as possible. The feeling disappeared when you realized it was a marathon. (WM-G)

\section{Sense of Community at Ward Manager Level}

When reflecting on the sense of community with other ward managers in the same department or across departments, some ward managers experienced that they were in a supportive collegial environment.

We (the ward managers in the same unit) met and talked. It is worth gold to have such colleagues. (...) We usually support and lean on each other - listen to one another and if you don't nourish that on a daily basis then it does not work at all during times of crisis. (WM-L)
The dominant narration was the opposite and ward managers described how they had felt isolated from colleagues and sometimes in combat regarding resources.

Between us, the ward managers in the department, there has been silos. (...) I wish more had been done to bring us together. (WM-H)

\section{Sense of Community at Executive Level}

Towards sense of community with the executive and head of department level, some ward managers expressed that they felt completely aligned with their head of departments they experienced being included and well informed.

My leaders have informed us about everything (...) if I gather all the information I have received it would be a thick book, almost like a bible. (WM-D)

Others felt completely isolated and left alone. These ward managers did not have any sense of community with their head of department. They expressed feelings of being at the bottom of the hospital management hierarchy and that their sense of community with the leaders above them was low.

It became a war between the departments because everyone wanted to shut the departments down and we had to distribute the patients ... and then there was a long way to the hospital director. (WM-B)

\section{Theme 3: Balancing Different Stakeholder Needs \\ Staff Needs versus Overall Needs}

Transferring or receiving temporary staff, forced the ward managers to balance the needs of their own staff with the overall needs of the situation. Despite considering some staff members as vulnerable due to personal circumstances or chronic illnesses, it was often not possible to meet the preferences and needs of staff. Examples could be units where no nurses volunteered to be transferred to work in the COVID-19 units but the ward manager had to appoint some against their preferences.

My staff had to be transferred and they felt insecure, overwhelmed and insufficient. (WM-I)

Ward managers also raised concerns about protective equipment, particularly because few helpful guidelines existed or lasted long enough to be properly implemented. This created a sense of abandonment or imbalance between having to act according to rules and experiencing that the rules were contradictory or sometimes illogical. 
I had to defend and transfer the information to my staff and it made no sense. So I just did it, I stopped reflecting on how and why - the orders were as they were. (WM-F)

Safety for patients and staff was a major concern among the ward managers, they experienced that keeping both staff and patients as safe as possible could be difficult.

The insecurity about how to best protect ourselves has taken up a lot of time. The patients should be treated well, but we also needed to protect ourselves. (WM-A)

\section{Loyalty to Own Leaders versus Staffs Need}

Generally, the ward managers described that under usual circumstances they felt loyalty towards their own leaders and to some extent to the executive management. However, this loyalty came under pressure during the COVID-19 pandemic.

I have missed that my nearest leaders contacted and informed me about what went on. Loyalty has sometimes been difficult because you do not feel that you get the knowledge you need. (WM-A)

Some ward managers protested when they disagreed with their own head of departments, for instance regarding protective equipment or transferring staff. Sometimes this made their leaders change their decisions.

\section{Upholding Guidelines versus Relatives' and Patients' Needs}

The COVID-19 pandemic resulted in the establishment of immediate restrictions of visitors at the hospitals and other health-care settings. This created inconvenient and ethically difficult situations in the units where the ward managers were responsible for upholding these limitations.

One of the biggest leadership challenges has been to take the relatives needs into account. The limited access of relatives has led to conflicts that I have taken responsibility for. (WM-M)

This made some ward managers compromise the guidelines out of consideration for the family, especially when the patients were seriously ill or dying.

Balancing different stakeholder needs also became a complex challenge in processes of patient discharge or re-admissions. This was caused by missing guidelines, and the ward managers' experiences increased risk of misunderstandings and unnecessary burdens for patients, relatives or the staff involved.
The restrictions with relatives' present have led to some conflicts with relatives which I have undertaken. One badmouthed me and called me various things but I'm pretty cool with that, there was not much else to do. (WM-M)

\section{Theme 4: Involvement in Decision-Making Top-Down Decision-Making}

It was an experience among the ward managers that decisions during the COVID-19 were taken and communicated in a hierarchical and top-down manner and that they were not involved enough despite most decisions concerning their domain, including responsibility for staff and patients. Under normal circumstances, it is the responsibility of the heads of departments to pass decisions from the executive management on to ward managers. However, this decision flow did not operate well according to the ward managers.

I experienced that my superiors went to information meetings with the hospital directors but all that information was not passed on. Why don't they involve the frontline leaders? (WM-H)

The CEO of the hospital, who was not in direct contact with the ward managers, sent a weekly e-mail or video greeting to all staff at the hospital, but the ward managers did not regard this as addressed to them, rather they had an experience of not being seen, valued or properly supported for their contribution.

Why don't they call us in? I mean, we have knowledge about what is going on. However, we were disconnected, knowledge is supposed to be transferred down to us, but you know how much is lost, through every layer. I simply don't understand why we are not regarded as more valuable. This is what makes you last for fewer years. (WM-L)

\section{Bottom-Up Decision-Making}

Some of the most experienced ward managers established small COVID-19 taskforces that helped them interpret and communicate the many and sometimes contradictory decisions that came on a daily, sometimes hourly, basis. This kind of taskforces could be at unit level.

When I stood with my back against the wall, I decided to establish a steering group with the hygiene nurse, an ITsuper-user and our quality assurance nurse. I said: now it is you, it is us, who take decisions, all staff can give their inputs, but it is this group that decides, and the staff thought it was a super solution. (WM-H) 
Another ward manager, who came from a minor, but very specialized area, described how she came in contact with similar units around the country and held Zoom meetings every week in order to share and compare decisions and experiences. This kind of leadership networking gave the ward manager a clear sense of having influence on the decisions made.

We quickly agreed to meet every Friday: how is this done nationally? (...) We gave each other practical advice in a situation where everything came top down and you felt you ran your forehead into the wall. When I realized what they did in other places, and had this kind of sparring I was able to lead a little upwards. (WM-L)

\section{Theme 5: Personal Development}

The ward managers' experiences of their own development during the COVID-19 situation ranged from being on a steep learning curve to being able to use valuable tools.

\section{Being on a Steep Learning Curve}

Some ward managers highlighted that the situation had made them more aware of the need to be much more open and honest about the situation despite their lack of overview and information. This could be very demanding and included a steep learning curve. Further, being able to contain frustrations based on decisions on which the ward managers had no influence created a sense of personal development. Some of the ward managers who themselves had been transferred to new tasks used the situation to reflect on their own practice and on how to handle situations differently in the future.

I have learned a lot and I would not do it the same way next time. I would have more dialogue with the staff. I have been much less empathetic and much tougher than I usually am, and I will strive to change that balance. (WM-C)

\section{Management Education Gives Valuable Tools}

Some of the ward managers expressed that their educational management background helped them in the situation and they felt relieved by being experienced and well educated.

My Master-education has been worth gold; you meet others and understand frustrations better. It has given me tools to understand this situation. I have been better at explaining to the staff. You learn to reflect at a different level, to keep calm, and use your network. (...) Through education you learn to use networks, and that it is ok not to know the answer to everything, you need to draw on others. (WM-L)

\section{Personal Development - Rewound}

However, some of the ward managers expressed that they did not experience personal development because their values were compromised and they could not be the leaders they wished to be.

I do not know if it has developed me as a leader. I feel like it has degraded me in many ways, as I could not be the leader I wished to be. I suddenly became an advanced shift planner. (WM-G)

Other ward managers expressed that they had not felt experienced, prepared or well enough educated to handle the crisis. Some of the ward managers who were newly appointed and had little leadership experience experienced particular situations that underlined the feelings of powerlessness.

On a personal level this (pandemic) has given much, I have never tried something like this before. It has given me experiences on where I do not wish to be in leadership and what I will tolerate (...) Perhaps I need to learn to say no, but it is difficult as a new leader to say no and that enough is enough. (WM-E)

Lack of formal management education also gave some of the ward managers the experience of not being able to handle the situation, as they would have liked to.

It could have been helped with education and experience; I just started my leadership education and had to stop it. I have no experience and I have acted solely on my gut feeling. (WM-E)

\section{Discussion}

The data in this study highlight the challenges that a crisis such as COVID-19 places on ward managers in a healthcare organization. Lessons learned from other crisis situations such as wars have made it clear that management models must be able to adapt to quickly changing circumstances and organizations need to reinvent themselves by creating common awareness, breaking down silos and increasing transparency in order to truly collaborate. $^{22}$

The interviews with ward managers illustrate the complex relationships that arise in such situations between what is espoused as "best practice" in leadership and 
what is experienced in reality. In the context of the espoused versus the reality of leadership practices, key issues emerge through the data analysis that needs to be carefully considered, in order to learn from such experiences and plan for future situations.

In contemporary leadership literature, the focus on leaders working from a place of shared values enabling all persons to flourish is privileged. ${ }^{23}$ This values-focus is seen in many models of leadership such as transformational leadership, situational leadership and especially in person-centred leadership. ${ }^{17,23,24}$ The outcome from person-centred leadership is that of facilitating the existence of a healthful culture in which decision-making is shared, staff relationships are collaborative, leadership is person-oriented, and innovative practices are supported. ${ }^{15}$ However, whilst we see evidence of the ward managers in this study striving for this kind of engagement, many found it challenging to do so. The challenge did not always relate to their own lack of knowledge or expertise (although there was evidence of this too) but primarily seemed to occur because of a conflict of values, ie, operating as a person-centred leader in an organizational context that was inherently hierarchical. This was evident in examples such as senior managers failing to include and inform ward managers about key decisions made at a senior level, which highlights a culture that is not one of shared values, or equality and respect, but instead one where information and knowledge is passed through leadership levels (from top to bottom).

In contemporary organizational theory, the shift from a management to a leadership focus is evident. ${ }^{25}$ Frederic Laloux makes this explicit in his work "reinventing organizations". ${ }^{26}$ Laloux argues that effective organizations privilege three practices that permeate all aspects and levels of organizational practice autonomy, trust and soulful-practices (well-being practices). Laloux demonstrated that when organizations privilege such practices, staff productivity and effectiveness is maximized and their well-being enhanced. ${ }^{26}$ In our study, we saw evidence of ward managers struggling with a "lack of acknowledgement" of the contribution they made in managing the crisis. Some of them felt that they were treated as objects by head of departments or the executive management for the dissemination of information and instructions rather than equal and active participants in shared decisionmaking. The consequence for some of the ward managers was self-doubt and a feeling of being outside of the decision-making process and thus an inability to direct the focus and place of change. This is an important finding and one that needs to be considered carefully in the way that organizations establish processes of engagement during times of crisis.

Whilst organizational executive leaders may consider a hierarchical "command and control" approach to management and leadership as an effective means of keeping control of a crisis, in reality, it has a negative impact on the front-line leaders who have the responsibility for implementing new practices, procedures and behaviours. Dewing and McCormack identified the need for a careful balance to be maintained between demands placed on a person's energy and their level of absorption, ie, the extent to which a leader is engrossed in their work. ${ }^{27}$ This lack of engagement and the negative consequence on leader's ability to absorb the demands for change being placed on them is evident in our data. Dewing and McCormack suggest that,

In the care environment, engagement can be a key to unlocking productivity and potential, and to transforming the working lives of many in healthcare for who may otherwise find work an effort and a drain on their energy and personal resources. ${ }^{27}$

Engagement is an essential quality of adult two-way relationships and when it is present, evidence suggests that goals are more easily achieved and teamwork improved. ${ }^{28}$ MacLeod and Clarke advocate that when staff are engaged they are more committed to the organization's goals, more motivated to contribute to the organization's success and have a greater ability to enhance their own sense of wellbeing. These are important messages to reflect on and consider in exploring how best to create a more engaged model of leadership consistent with person-centred values.

The lack of engagement with some of the ward managers is also reflected in their sense of being inadequately prepared for their role. The data highlighted that some of the ward managers did not feel they had the right kind or level of education to help them effectively undertake their role.

Being faced with a crisis such as COVID-19 brought the preparation of leaders into a sharp focus. Some of the ward managers felt isolated and not being part of a supportive or engaged network of leaders that enabled continuous learning. Some ward managers highlighted a need for foundational knowledge in leadership practices that would enable them to make more effective decisions 
"in the moment". Eide and Cardiff highlight that personcentred leaders balance issues of performance and commitment of team members with a primary focus on empowerment and well-being. ${ }^{17}$ This balancing act enables what Cardiff calls "coming into own" as a leader, that is, when leaders feel that things are "right" because staff are reaching their potential and being authentic. ${ }^{17}$ The challenges associated with engaging in this kind of leadership were evident in the data that focused on ward managers' difficulties in knowing what to do when staff were non-voluntarily deployed from different departments, when staff were distressed or when conflicting and contrasting information was passed to them to deal with. These examples of complex management situations require a high level of facilitation from ward managers and without adequate preparation, it is unsurprising that they struggled in these contexts. In noncrisis situations, such facilitative leadership should happen through contextualized learning and practice development in practice but in times of crisis, doing this kind of work is often suspended or at best integrated into everyday leadership practices. ${ }^{29}$ However, without a sound foundation of such knowledge and skills established among ward managers, this cannot happen and leaders may resort to crisis interventions with the resulting feelings of isolation and doubt.

\section{Limitations}

Directed content analysis as an analytical approach can be critiqued because the use of predetermined theory can mean that the researchers are more likely to find evidence that is supportive of the given theory. ${ }^{21}$ However, all authors were aware of this in the collaborative discussion of the results of the analysis of the interviews and included an extra thorough examination of the findings. Thirteen ward managers were interviewed about their experiences during the first COVID-19 wave, which may be regarded as a small number of participants. However, the numbers of participants in a qualitative study must first and foremost support a new and rich understanding of the investigated phenomenon. ${ }^{30}$ This is to our best judgement and experience the case in this study.

\section{Conclusion}

The nurse ward managers, who worked in the frontline of the first COVID-19 pandemic often experienced lack of acknowledgement and information from the head of departments, their values were challenged and sometimes they were unsure of their own competencies. These factors, combined with the experience of not being able to authentically facilitate the leadership one desires, may lead to lack of engagement, which in a time of crisis may have serious consequences for patient safety, staff wellbeing and turnover, and for the leaders themselves.

If an organization espouses person-centred values then hierarchical and controlling practices should be challenged and reoriented towards collaborative, inclusive and participative practices of engagement and involvement.

This study highlights the importance of leadership development being an established and integrated component of organizations, so that ward managers are able to sustain person-centred ways of being and doing in times of crisis.

\section{Data Sharing Statement}

Anonymized data can be obtained by contacting the first author Professor Bibi Hølge-Hazelton, bibh@regionsjaelland.dk.

\section{Ethical Considerations}

Permission to conduct the study was received from the hospital executive management. All participants were initially informed about anonymity and their ability to withdraw from the study. Prior to the interviews, all participants signed and returned a consent form to participate in the study, including that the anonymized responses could be used for publication. The Danish Data Protection Agency (REG-026-2020) and The National Committee on Health Research Ethics (J.nr. 20-000013) approved the study. This study was conducted in accordance with the principles of the Declaration of Helsinki. ${ }^{31}$

\section{Author Contributions}

All authors made a significant contribution to the work reported, whether that is in the conception, study design, execution, acquisition of data, analysis and interpretation, or in all these areas; took part in drafting, revising or critically reviewing the article; gave final approval of the version to be published; have agreed on the journal to which the article has been submitted; and agree to be accountable for all aspects of the work.

\section{Funding}

There were no sources of funding. 


\section{Disclosure}

The authors report no conflicts of interest in this work.

\section{References}

1. Roser M, Ritchie H, Ortiz-Ospina E, Hasell J. Coronavirus Pandemic (COVID-19). Our World Data. https://ourworldindata.org/corona virus. Accessed February 12, 2021.

2. European Centre for Disease Prevention and Control. COVID-19 situation update worldwide, as of week 5, [Updated February 11, 2021]. https://www.ecdc.europa.eu/en/geographical-distribution -2019-ncov-cases. Accessed February 12, 2021.

3. European Centre for Disease Prevention and Control. Situation update worldwide, as of 10 April 2020; 2020. https://www.ecdc europa.eu/en/geographical-distribution-2019-ncov-cases. Accessed April 11, 2020.

4. Rosser E, Westcott L, Ali PA, et al. The need for visible nursing leadership during COVID-19. J Nurs Scholarsh. 2020:2-3. doi:10.1111/jnu.12587

5. Hølge-Hazelton B, Kjerholt M, Rosted E, Hansen ST, Borre LZ, McCormack B. Health professional frontline leaders' experiences during the COVID-19 pandemic: a cross-sectional study. J Healthc Leadersh. 2020;2021(13):7-18. doi:10.2147/JHL.S287243

6. Kodama Y, Fukahori H. Nurse managers' attributes to promote change in their wards: a qualitative study. Nurs Open. 2017;4 (4):209-217. doi:10.1002/nop2.87

7. Saleh U, O'Connor T, Al-Subhi H, Alkattan R, Al-Harbi S, Patton D. The impact of nurse managers' leadership styles on ward staff. $\mathrm{Br}$ J Nurs. 2018;27(4):197-203. doi:10.12968/bjon.2018.27.4.197

8. Pegram AM, Grainger M, Sigsworth J, While AE. Strengthening the role of the ward manager: a review of the literature. J Nurs Manag. 2014;22(6):685-696. doi:10.1111/jonm.12047

9. Hølge-Hazelton B, Berthelsen CB. Leading unique cultures in departments with low turnover of nurses. A positive deviance approach study. J Nurs Manag. 2020. doi:10.1111/jonm.13061

10. Cardiff S, McCormack B, McCance T. Person-centred leadership: a relational approach to leadership derived through action research. J Clin Nurs. 2018;27(15-16):3056-3069. doi:10.1111/jocn.14492

11. Tong A, Sainsbury P, Craig J. Consolidated criteria for reporting qualitative research (COREQ): a 32-item checklist for interviews and focus groups. Int J Qual Health Care. 2007;19(6):349-357. doi:10.1093/intqhe/mzm042

12. McCormack B, McCance TV. Development of a framework for person-centred nursing. $J \quad A d v$ Nurs. 2006;56(5):472-479. doi:10.1111/j.1365-2648.2006.04042.x

13. World Health Organization. Pandemic Influenza preparedness and response: a WHO guidance document; 2009. http://www.ncbi.nlm. nih.gov/books/NBK143062/. Accessed July 27, 2020.

14. Hølge-Hazelton B, Kjerholt M, Rosted E. Health professional frontline leaders' experiences during the COVID-19 pandemic. A cross sectional study. J Healthc Leadersh Manuscr Accept. 2021;13:7.
15. McCormack B, van Dulmen S, Eide H, Skovdahl K, Eide T. PersonCentred Healthcare Research. Wiley-Blackwell; 2017.

16. McCormack B, Titchen A. Critical creativity: melding, exploding, blending. Educ Action Res. 2006;14(2):239-266. doi:10.1080/ 09650790600718118

17. Eide T, Cardiff S. Leadership Research: a Person-Centred Agenda. In: Person-Centred Healthcare Research. Wiley-Blackwell; 2017:95-116.

18. Drabble L, Trocki KF, Salcedo B, Walker PC, Korcha RA. Conducting qualitative interviews by telephone: lessons learned from a study of alcohol use among sexual minority and heterosexual women. Qual Soc Work QSW Res Pract. 2016;15(1):118-133. doi:10.1177/1473325015585613

19. Mealer M, Jones J. Methodological and ethical issues related to qualitative telephone interviews on sensitive topics. Nurse Res. 2014;21(4):32-37. doi:10.7748/nr2014.03.21.4.32.e1229

20. Mikuska E. The Importance of Piloting or Pre-Testing SemiStructured Interviews and Narratives. Sage Publications Ltd; 2017; doi: $10.4135 / 9781473977754$

21. Hsieh H-F, Shannon SE. Three approaches to qualitative content analysis. Qual Health Res. 2005;15(9):1277-1288. doi:10.1177/ 1049732305276687

22. McChrystal GS, Silverman D, Collins T, Fussell C. Team of Teams: New Rules of Engagement for a Complex World. Penguin UK; 2015.

23. Sfantou DF, Laliotis A, Patelarou AE, Sifaki- Pistolla D, Matalliotakis M, Patelarou E. Importance of Leadership style towards quality of care measures in healthcare settings: a systematic review. Healthcare. 2017;5(4):4. doi:10.3390/healthcare5040073

24. Caldwell C, Dixon RD, Floyd LA, Chaudoin J, Post J, Cheokas G. Transformative leadership: achieving unparalleled excellence. $J$ Bus Ethics. 2012;109(2):175-187. doi:10.1007/s10551-011-1116-2

25. Algahtani D. Are leadership and management different? A Review. J Manag Policies Pract. 2014;2:3. doi:10.15640/jmpp.v2n3a4

26. Laloux F. Reinventing Organizations: A Guide to Creating Organizations Inspired by the Next Stage in Human Consciousness. Nelson Parker; 2014.

27. Dewing J, McCormack B. Queen Margaret University, Edinburgh. Engagement: a critique of the concept and its application to person-centred care. Int Pract Dev J. 2015;5(Suppl):1-10. doi:10.19043/ipdj.5SP.008

28. MacLeod D, Clarke N. Engaging for success. Enhancing Perform Empl Engagem. 2009.

29. Harvey G, Kelly J, Kitson A, Thornton K, Owen V. Leadership for evidence-based practice-Enforcing or enabling implementation? Collegian. 2020;27(1):57-62. doi:10.1016/j.colegn.2019.04.004

30. Sandelowski M. Sample size in qualitative research. Res Nurs Health. 1995;18(2):179-183. doi:10.1002/nur.4770180211

31. WMA Declaration of Helsinki. Ethical principles for medical research involving human subjects; 2020. https://www.wma.net/poli cies-post/wma-declaration-of-helsinki-ethical-principles-for-medicalresearch-involving-human-subjects/. Accessed April 11, 2020.
Risk Management and Healthcare Policy is an international, peerreviewed, open access journal focusing on all aspects of public health, policy, and preventative measures to promote good health and improve morbidity and mortality in the population. The journal welcomes submitted papers covering original research, basic science, clinical \& epidemiological studies, reviews and evaluations, guidelines, expert opinion and commentary, case reports and extended reports. The manuscript management system is completely online and includes a very quick and fair peer-review system, which is all easy to use. Visit http://www.dovepress.com/testimonials.php to read real quotes from published authors. 